\title{
PRIMARY MYXOPAPILLARY EPENDYMOMA OF FOURTH VENTRICLE: FIRST CASE REPORT IN A TWO-YEAR-OLD CHILD
}

\author{
Uzma Bukhari', Durr-e-Sameen Kamran', Hira Salam ${ }^{1 凶}$
}

\section{ABSTRACT}

Myxopapillary ependymoma (MPE), a rare pathological subtype of ependymoma which shows predilection for middle-aged adults between third and fifth decades of life. It is a benign tumor that primarily occurs at filum terminale of spinal cord with a rare possibility to metastasize to the brain. Primary intracranial MPEs have been reported only rarely. Two-year-old child presented with a space-occupying lesion in fourth ventricle. Based on clinical and radiological findings, particularly owing to patient's age differential diagnosis of medulloblastoma was considered. Biopsy followed by histopathological and immunohistochemical analysis yielded diagnosis of primary intracranial myxopapillary ependymoma.

In conclusion, MPEs can occur anywhere in intracranial space and in any age group. Despite their indolent behavior, their metastatic potential necessitates thorough investigation to rule out former before establishing diagnosis of primary intracranial MPE.

KEY WORDS: Ependymoma (MeSH); Ependymoma, Myxopapillary (MeSH); Brain Tumor (MeSH); Fourth Ventricle (MeSH); Ependymoglial Cells (MeSH); Brain Neoplasms (MeSH); Pediatric brain tumor (Non-MeSH); WHO grade I (Non$\mathrm{MeSH})$; Neoplasm Grading (MeSH); Immunohistochemistry (MeSH); Children, Preschool (MeSH).

THIS ARTICLE MAY BE CITED AS: Bukhari U, Kamran D-S, Salam H. Primary myxopapillary ependymoma of fourth ventricle: first case report in a two-year-old child. Khyber Med Univ J 2020;12(I):58-60. DOI: I0.35845/kmuj.2020.19677.

\section{INTRODUCTION}

$M$ yxopapillary ependymoma (MPE), a rare pathological subtype of ependymoma which shows predilection for middle aged adults between third and fifth decades of life.' Despite being categorized under World Health Organization (WHO) Grade-I tumors, MPE harbors tendency for both local relapse and distant spread. 'The tumor has strong predilection for involvement of filum terminale of spinal cord, but MPE can manifest rarely in uncommon sites including brain and subcutaneous tissue. ${ }^{2-4}$ According to one series, MPE constituted merely $0.3 \%$ of all CNS tumors in the pediatric age group. 4 According to literature review, only 17 cases of primary intracranial MPEs have been reported. ${ }^{3,5}$ We present first case of primary intracranial MPE in 2-year-old child, youngest age recorded to date.

\section{CASE REPORT}

Two-year-old child presented with a space-occupying lesion in fourth ventricle. On radiological examination, MRI revealed an intraventricular mass lesion in fourth ventricle resulting in obstructive hydrocephalus. No calcifications or hemorrhage were seen. Based on clinical findings, differential diagnosis of medulloblastoma was considered (Figure I). Biopsy was performed, and specimen sent for histopathological examination for establishment of diagnosis.

Grossly, the biopsy material comprised of multiple pale white soft tissue pieces measuring $4 \times 3 \times 2 \mathrm{~cm}$, collectively. Microscopically, sections examined revealed neoplastic lesion exhibiting characteristic papillary architecture and cuboidal to elongated neoplastic cells with fibrillary background. Individual neoplastic cells show hyperchromatic, vesicular
I. Dow International Medical and Denta College, Ojha Campus, Karachi, Pakistan.

Email ${ }^{\otimes}$ :hirasalam@gmail.com
Date Submitted:

Date Revised:

Date Accepted:
September 03, 2019
February 25, 2020

February 27,2020

nuclei, small nucleoli and pale cytoplasm. Perivascular pseudo-rosette formation was also noted. Occasional mitotic figures were seen with mitotic count of I-2 per 10 high power fields. No evidence of increased cellularity, increased mitoses or necrosis was noted. Abundant perivascular mucin with microcyst formation was noted, highlighted on special stain alcian blue (Figure 2). Focally reactive glial tissue is noted.

Immunohistochemical staining was performed and tumor cells were reactive against glial fibrillary acidic protein (GFAP), vimentin and SI00. No reactivity was noted against pan-cytokeratin (Figure 3).

Based on radiological and histopathological features, diagnosis of primary intracranial myxopapillary ependymoma was established. Spinal cord MRI excluded possibility of metastasis.

\section{DISCUSSION}

Ependymomas are relatively uncommon neoplasms of ependymal cell origin constituting $6 \%$ of all gliomas, $60 \%$ of spinal gliomas, and up to $90 \%$ of primary tumors of cauda equina and filum terminale. ${ }^{6,7}$ MPE was first described as a distinct morphological variant of former by Kernohan in 1932 based on histological findings of papillary architecture, perivascular pseudorosettes and abundance of mucin. ${ }^{4,6}$

MPEs are slow-growing, WHO grade I tumors manifesting almost exclusively as intraspinal lesions in $3^{\text {rd }}$ or $4^{\text {th }}$ decade of life. ${ }^{7}$ Slight male predilection with male-tofemale ratio of I.7:I has been reported. In children, the neoplasm tends to behave more aggressively with greater propensity for CNS metastasis. ${ }^{8}$ Metastases may develop, albeit rarely, through dissemination via cerebrospinal fluid (CSF) circulation. ${ }^{7,9}$ Before diagnosis of primary intracranial MPE can be established, radiological imaging of both brain and spinal cord are mandatory. ${ }^{10}$ 


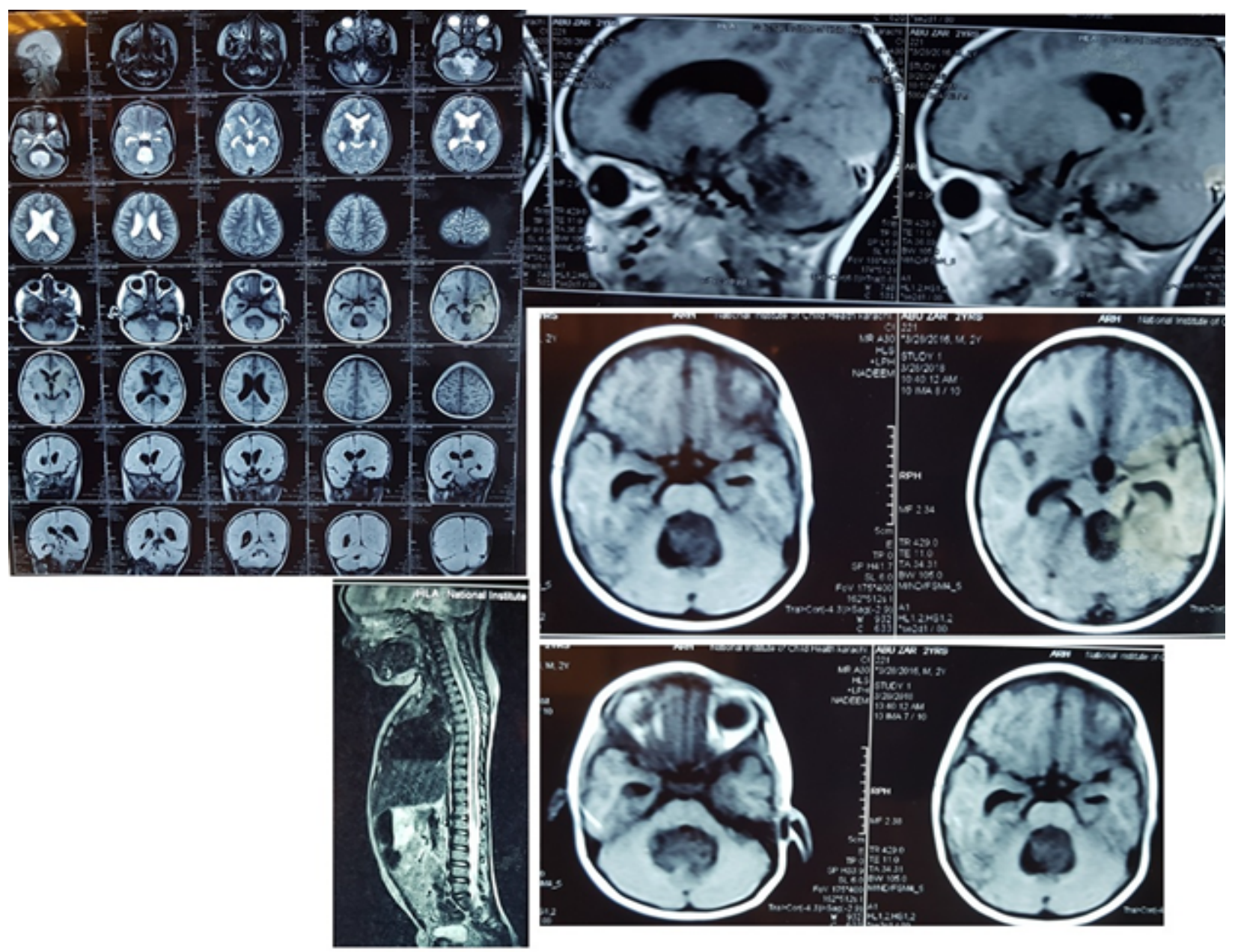

Figure I: MRI scans showing intraventricular mass resulting in obstructive hydrocephalus. No evidence of calcification or hemorrhage is seen. No lesion was noted in Spinal cord

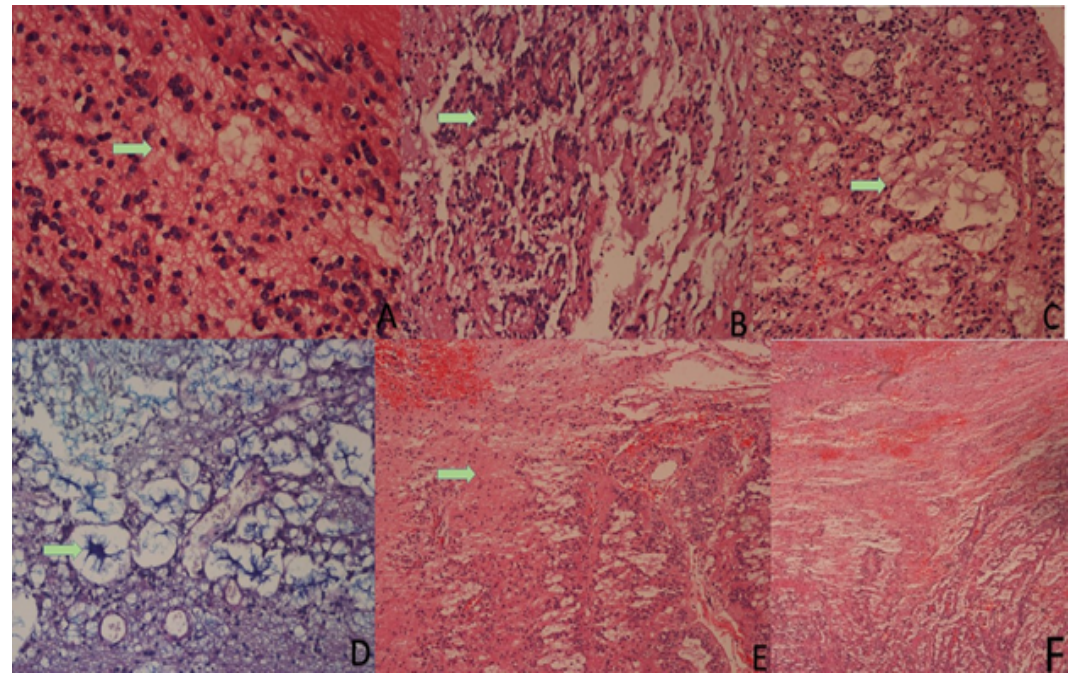

Figure 2: Hematoxylin and Eosin (H\&E) stained sections showing: A: occasional mitotic figures and fibrillary background, B: Perivascular pseudorosette formation, C: Microcyst formation, D: Acidic mucin in cystic spaces (PAS Alcian blue), and E - F: Adjacent reactive brain tissue showing foci of hemorrhage. No evidence of necrosis was seen.
Only 17 cases of primary intracranial MPEs have been reported prior to this case. Only three cases have been reported in fourth ventricle, all of which have been females with youngest age at diagnosis recorded at 7 years, which is also the youngest age in which primary intracranial MPEs have been reported up until now. Our case is first to report involvement of fourth ventricle in male patient and youngest age, i.e. 2 years.'

In conclusion, MPEs can occur anywhere in intracranial space and in any age group. Despite their indolent behavior, their metastatic potential necessitates thorough investigation to rule out former before establishing diagnosis of primary intracranial MPE.

\section{REFERENCES}

I. Wang H, Zhang S, Rehman SK, Zhang $Z$, Li W, Makki MS, et al. 


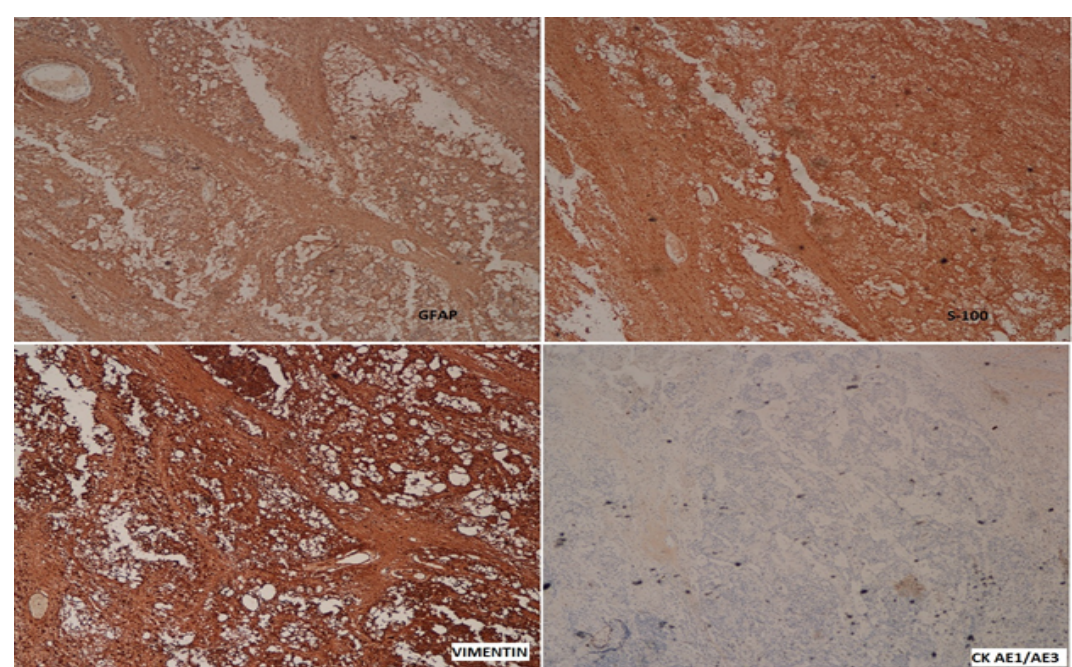

Figure 3: Positive immunohistochemical staining against GFAP, SIO0 and Vimentin. Negative immunohistochemical staining against Cytokeratin AEI/AE3.

Clinicopathological features of myxopapillary ependymoma. J Clin Neurosci 20I4;2 I(4):569-73. DOI: 10.1016/j.jocn.2013.05.028.

2. Salomao JF, de Andrade CV, Bellas AR, Cervante TP. The nature of double concomitant myxopapillary ependymoma: report of a case. Child's Nerv Sys 2014;30(3):527-30. DOI: I0.1007/s0038I-013-225I-0.

3. Khalatbari MR, Moharamzad Y. Primary cerebral myxopapillary ependymoma presenting with intratumoral hemorrhage. $\mathrm{Br}$ J Neurosurg 2014;28(4):523-4. DOI: 10.3109/02688697.20I3.859656.

4. Cimino PJ, Agarwal A, Dehner LP. Myxopapillary ependymoma in children: a study of II cases and a comparison with the adult experience. Pediatr Blood Cancer 20I4;6I(II):1969-7I. DOI: I0.1002/ pbc. $25 \mid 25$.

5. Patangia P, Rai NN, Saxena R, Mandawat PS. Primary intracerebral myxopapillary ependymoma: A rare case report. Annals Pathol Lab Med 2016;3(5):C236-40.

6. Rogers $S$, Jones $D T$, Ireland $A$, Gottardo NG, Endersby R. Unusual paediatric spinal myxopapillary ependymomas: Unique molecular entities or pathological variations on a theme? J Clin Neurosci 2018;50:1448. DOI: 10.1016/j.jocn.2018.01.048.

7. DiLuna ML, Levy GH, Sood S, Duncan CC. Primary myxopapillary ependymoma of the medulla: case report. Neurosurgery 2010;66(6): EI 208-9; discussion E9. DOI: 10.1227 /0I.NEU.00003695 I3.84063.A6

8. Lucchesi KM, Grant R, Kahle KT, Marks AM, DiLuna ML. Primary spinal myxopapillary ependymoma in the pediatric population: a study from the Surveillance, Epidemiology, and End Results (SEER) database. J Neurooncol 2016;130(I):133-40. DOI: $10.1007 / \mathrm{s} \mid 1060-016-2218-6$.

9. Mewada TB, Bishnoi IH, Singh $H$, Singh D. Occipital Intraparenchymal Myxopapillary Ependymoma: Case Report and Literature Review. Asian J Neurosurg 2017;12(4):73I-4. DOI: 10.4103/ajns.AJNS_45_15.

10. Margetis K, Koutsarnakis C, Stranjalis G. Primary cerebellar myxopapillary ependymoma. J Neurooncol 20I I; 104(3):839-40. DOI: 10.1007/s | |060-0| |-0535-3.

\section{AUTHORS' CONTRIBUTIONS}

Following authors have made substantial contributions to the manuscript as under:

UB \& DeSK: Identification, diagnosis \& management of the case, critical review, final approval of the version to be published.

HS: Diagnosis, drafting the manuscript, final approval of the version to be published.

Authors agree to be accountable for all aspects of the work in ensuring that questions related to the accuracy or integrity of any part of the work are appropriately investigated and resolved.

CONFLICT OF INTEREST
Authors declared no conflict of interest
GRANT SUPPORT AND FINANCIAL DISCLOSURE
NIL

This is an Open Access article distributed under the terms of the Creative Commons Attribution-Non Commercial 2.0 Generic License.

KMUJ web address: www.kmuj.kmu.edu.pk

Email address: kmuj@kmu.edu.pk 